\title{
A Case Against Fancy Decorated Drinks: Multi-Organ Failure After Drinking a Mojito Cocktail
}

\author{
Simon Theodore Bac, Eric Frans van Bommel \\ Department of Internal Medicine and Gastroenterology, Albert Schweitzer Hospital, Dordrecht, The Netherlands
}

\section{Doi: 10.12890/2016_000479- European Journal of Case Reports in Internal Medicine - C EFIM 2016}

Received: 08/08/2016

Accepted: $25 / 08 / 2016$

Published: 06/09/2016

How to cite this article: Bac ST, van Brommel EF. A case against fancy decorated drinks: multi-organ failure after drinking a mojito cocktail. EJCRIM 2016;3: doi:10.12890/2016_000479.

Conflicts of Interests: The Authors declare that there are no competing interests.

This article is licensed under a Commons Attribution Non-Commercial 4.0 License

\section{ABSTRACT}

We present the first case of gastro-intestinal perforation caused by a mint twig decorating a cocktail drink. A 76-year-old man was enjoying his Mojito cocktail on a cruise ship near Mexico when he accidently swallowed a mint twig, resulting in ileum perforation. This led to a cascade of events, eventually resulting in life-threatening multi-organ failure. Given this rare but potentially severe complication and the increasing popularity of decorated drinks, a less 'fancy' presentation for cocktails and similar drinks may be warranted.

\section{LEARNING POINTS}

- Accidental ingestion of a foreign body is relatively common.

- Although rare, the presence of foreign bodies in the gastro-intestinal tract can result in an acute surgical abdomen requiring emergency surgery.

- Drinks decorated with plant twigs may be a risk factor for an acute surgical abdomen and consequently are not recommended.

\section{KEYWORDS}

Mojito cocktail; mint twig; ileum perforation; multi-organ failure.

\section{CASE REPORT}

In January 2014, a 76-year-old man was enjoying his retirement with a boat cruise in the seas off Mexico, and was sitting on deck drinking a Mojito cocktail. This popular drink contains rum mixed with fresh mint leaves and lime juice poured over crushed ice and topped with soda water. While drinking, the passenger accidentally swallowed a small twig of mint leaves. He soon developed acute and progressive abdominal pain and was admitted to a nearby Mexican hospital, where he was diagnosed with an acute abdomen.

Laparoscopy revealed purulent peritonitis due to perforation of the ileum, which was repaired surgically. However, the patient's condition deteriorated and he developed progressive respiratory failure. Because of ongoing peritonitis, intestinal leakage was suspected and a laparotomy was performed which resulted in the construction of an ileostomy. During this operation the cause of the gastro-intestinal (GI) perforation was discovered: a mint twig from the Mojito cocktail (Fig. 1). The patient's subsequent clinical course was severely complicated, necessitating prolonged mechanical ventilation and renal replacement therapy. After stabilization, he was transported to the Netherlands and admitted to our hospital. The patient was in a delirious state and cachectic, critical illness neuropathy was present and renal replacement therapy was still required. He slowly recovered, but at the time of his latest follow-up, 4 months after hospital discharge, severe renal failure has not resolved and intermittent haemodialysis is still required. 


\section{DISCUSSION}

We present the first case of $\mathrm{GI}$ perforation leading to multi-organ-failure caused by consumption of a cocktail decorated with mint twigs, as is popular in many drinks. It shows that an apparently harmless beverage can lead to potentially life-threatening problems. We already know that accidental ingestion of a foreign body is relatively common in adults and can happen unnoticed. However, GI complications are unusual, particularly in the presence of normal bowel physiology ${ }^{[1,2]}$. More than $90 \%$ of foreign bodies which reach the stomach pass through the intestine without problem because of the remarkable ability of the intestine to protect itself. When a sharp foreign body comes in contact with the intestinal mucosa, the bowel wall increases the diameter of the lumen on that side, thus allowing the foreign body to continue to pass through the GI tract. However, foreign bodies can still pierce the intestine, as in our case, most likely in areas with anatomic narrowing (the pylorus, duodenal sweep, terminal ileum and anus), physiological angles (curvature of the duodenum) or pathological strictures. The terminal ileum is the most common perforation site and most likely was the perforation site in our patient as well. One of the main complications of swallowed foreign bodies is perforation. However, perforation of the GI tract by accidentally ingested foreign bodies is rare, ingested fish bones being the most common cause $\mathrm{e}^{[2]}$. Other rare causes include ingestion of chicken bones, tooth picks and lollipop sticks ${ }^{[3]}$. Henceforth, we can add fancy looking cocktails decorated with mint twigs to this list.

Given the rare but serious complications described in our case report and the increasing popularity of decorated drinks, a less 'fancy' appearance for cocktails and similar drinks may be warranted.

\section{REFERENCES}

1. Mesina C, Vasile I, Vilcea DI, Pasalega M, Calota F, Parvanescu H, et al. Problems of diagnosis and treatment caused by ingested foreign bodies. Chirurgia (Bucur) 2013;108:400406.

2. Choi Y, Kim G, Shim C, Kim D, Kim D. Peritonitis with small bowel perforation caused by a fish bone in a healthy patient. World J Gastroenterol 2014;20:1626-1629.

3. Cho E, Lee D, Hong H, Park C, Park S, Kim H, et al. An unusual case of duodenal perforation caused by a lollipop stick: a case report. Clin Endosc 2014;47:188-191. 